\title{
Anti-Inflammatory Potentials of the n-Hexane Fraction of Alstonia boonei Stem Bark in
} Lipopolysaccharide-Induced Inflammation in Wistar Rats

\author{
John Oludele Olanlokun (D) \\ Adeola Oluwakemi \\ Olowofolahan' \\ Olusola Bodede (iD $)^{2}$ \\ Adekunle Theophilus \\ Adegbuyi $^{3}$ \\ Gerhard Prinsloo (iD ${ }^{2}$ \\ Paul Steenkamp ${ }^{4}$ \\ Olufunso Olabode \\ Olorunsogo'
}

'Laboratories for Biomembrane Research and Biotechnology, Department of Biochemistry, College of Medicine, University of Ibadan, Ibadan, Nigeria;

${ }^{2}$ Department of Agriculture and Animal Health, University of South Africa, Florida Campus, Florida, I7I0, South Africa;

${ }^{3}$ Department of Pharmacology and Therapeutics, Faculty of Pharmacy, Federal University, Oye-Ekiti, Nigeria; ${ }^{4}$ Research Centre for Plant Metabolomics, Department of Biochemistry, University of Johannesburg, Johannesburg, 2006, South Africa

Correspondence: John Oludele Olanlokun

Laboratories for Biomembrane Research and Biotechnology, Department of Biochemistry, Faculty of Basic Medical

Sciences, College of Medicine, University of Ibadan, Room NB 305, Ibadan, Nigeria Tel +23480380l420l

Email jodel72000@yahoo.com;

jo.olanlokun@mail.ui.edu.ng
Background: Inflammation is a protective response of the host to infections and tissue damage and medicinal plants have been used to regulate inflammatory response. The phytochemical contents of the $n$-hexane fraction of Alstonia boonei and their anti-inflammatory potentials in lipopolysaccharide-induced inflammation were investigated in rat liver.

Materials and Methods: A quantity of $5 \mathrm{mg} / \mathrm{kg}$ lipopolysaccharide (LPS) was used to induce inflammation in twenty-five male Wistar rats, grouped $(n=5)$ and treated as follows: negative control (10 mL/kg saline), positive control (1 mg/kg ibuprofen); 50, 100 and $20 \mathrm{mg} / \mathrm{kg}$ of the $n$-hexane fraction of Alstonia boonei were administered to test groups. In another experiment, twenty rats ( $\mathrm{n}=5$, without LPS) were administered the same doses of the $n$-hexane fraction of A. boonei and ibuprofen for seven days. At the end of the experiment, animals were sacrificed, serum was obtained from blood and liver mitochondria isolated in a refrigerated centrifuge. Mitochondrial permeability transition $(\mathrm{mPT})$ pore opening and mitochondrial $\mathrm{F}_{0} \mathrm{~F}_{1}$ ATPase

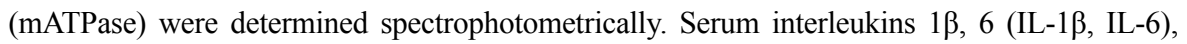
tumour necrosis factor alpha (TNF- $\alpha)$, C-reactive protein (CRP) and creatine kinase (CK), gamma glutamyl transferase (GGT), aspartate and alanine aminotransferases (AST and ALT, ) of the animals in which inflammation was induced using LPS but treated with graded doses of $n$-hexane fraction of $A$. boonei were determined using the ELISA technique. The phytochemical contents of the $n$-hexane fraction of $A$. boonei were determined using ultra performance liquid chromatography-tandem mass spectrometer (UHPLC-MS).

Results: Calcium induced $\mathrm{mPT}$ in 8 fold and LPS induced $\mathrm{mPT} 14$ fold in the negative control while the $n$-hexane fraction reversed $\mathrm{mPT}$ in the treated groups $(50,100$ and $200 \mathrm{mg} / \mathrm{kg})$ to 2, 4, 4 folds, respectively. LPS treatment of the negative group enhanced $F_{0} F_{1}$ mATPase activity, increased CRP, TNF- $\alpha$, IL-1 $\beta$, IL-6 levels as well as CK, AST, ALT and GGT activities. These values were significantly reduced by 100 and $200 \mathrm{mg} / \mathrm{kg}$ of the $n$-hexane fraction. UHPLC-MS analysis of the fraction revealed the presence of terpenoids, phenolics and sphingolipids.

Conclusion: These results showed that bioactive phytochemicals present in the $n$-hexane fraction of $A$. boone $i$ were not toxic, have an anti-inflammatory effect and could be used for the treatment of inflammatory diseases.

Keywords: Alstonia boonei, endotoxins, inflammatory cytokines, liquid chromatography-mass spectrometry

\section{Introduction}

Medicinal plants play important roles in the curative and preventive measures against diseases and are commonly in use in Africa and Asia. They are rich sources 
of phytochemicals that have the potentials of drug candidates. Till now, phytochemicals isolated from medicinal plants have been optimized to be promising sources of novel drugs. ${ }^{1}$ In spite of the frequent use, dependence and cost effectiveness of medicinal plants in Africa, only a few of these have been fully explored or their folkloric use been experimentally substantiated although they have been used for the treatment of malaria, dysentery, diarrhea, cough and inflammation. ${ }^{2-8}$

Inflammation is the response of the body's immune system to toxins, damaged cells and infections. At the tissue level, several features of inflammation include redness, associated pain, swelling, heat and loss of tissue function. ${ }^{9}$ Inflammation may induce severe consequences in the heart, kidney, lungs and liver leading to organ damage and failure. Though moderate inflammation of the liver has protective potential against injury and infection, excessive inflammation of this tissue can lead to injury and loss of liver cells. ${ }^{10}$

Inflammation occurs in the liver via both infectious and non-infectious agents. The infectious agents, such as bacteria and Plasmodium species, cause inflammation in the liver via the activation of some pathways by the secreted lipopolysaccharide (LPS). ${ }^{11}$ During inflammation, secreted proteins such as cytokines eg, interleukins, C-reactive proteins, tumour necrosis factor, malondialdehyde and thiobarbituric acid reactive substances (TBARS) are markers for inflammation. In addition to this, creatine kinase, an enzyme that is associated with cellular energy metabolism, has been associated with inflammation. ${ }^{12-19}$

It has been demonstrated that chronic inflammation can lead to deleterious effects such as cell death in cells and tissues. In fact, there is a crosslink between inflammation and cell death because cell death can be the consequence and cause of inflammation. Apoptosis is a form of cell death that may occur through the death receptor-mediated (extrinsic) or mitochondrial-mediated (intrinsic) pathway. $^{20,21}$ While apoptosis can be activated through the extrinsic pathway in response to the death receptors to extracellular signaling such as tumour necrosis factor (TNF) or TNF-related apoptosis inducing factor (TRAIL), the intrinsic pathway is characterized by mitochondrial outer membrane permeabilisation (MOMP) or mitochondrial membrane permeability transition (mPT) pore opening. The $\mathrm{mPT}$ therefore, remains one of the critical events that may occur during chronic inflammation. ${ }^{22-25}$

Alstonia boonei is a medicinal plant that has been shown to have anti-inflammatory potentials in folkloric medicine. ${ }^{26}$ It contains some phytochemicals such as flavonoids, phenolics, alkaloids and terpenes. Previous studies have shown that terpenes are essential phytochemicals with a great variety of pharmacological properties such as antimicrobial, antimalarial, anticancer and anti-inflammatory potentials. ${ }^{27}$ The age long use of nonsteroidal antiinflammatory drugs and steroids presents a plethora of undesirable consequences making the search for new cost effective anti-inflammatory drugs with minimal side effects inevitable. It is against this background that we investigated the anti-inflammatory potentials of the $n$-hexane fraction of the stem bark extract of $A$. boonei in a rat model.

\section{Materials and Methods Plant Collection and Preparation of the $n$-Hexane Fraction of Alstonia boonei}

Collection and authentication of the plant, as well as extraction and preparation of the methanol extract of the plant have been described in a previous study. ${ }^{28}$ Briefly, the stem bark of Alstonia boonei was collected, air-dried, blended into fine powder $(1 \mathrm{~kg})$ and soaked in sufficient methanol for 72 hours after which it was decanted, filtered and concentrated at $40{ }^{\circ} \mathrm{C}$ under reduced pressure using a rotary evaporator (Stuart, United Kingdom). The methanol extract was further concentrated to a solvent-free crude extract in a water bath (DK-420, China) until constant weight (56 g) was obtained.

The methanol extract of $A$. boonei (56 g) was preadsorbed on thin layer chromatography (TLC) silica gel $(60 \mathrm{~g})$ and loaded on a vacuum liquid chromatography column packed with TLC gel under pressure using $n$-hexane. The column was eluted with the solvent until exhaustion. The $n$-hexane fraction obtained was concentrated under reduced pressure using a rotary evaporator and further concentrated to a solvent free fraction in a water bath at $50{ }^{\circ} \mathrm{C}$. This fraction was kept in a refrigerator until used. A stock solution of $5 \%$ of the $n$-hexane fraction was prepared by dissolving $5 \mathrm{~g}$ of the fraction in $100 \mathrm{~mL}$ of corn oil and kept in the refrigerator.

\section{Ethical Consideration}

Animals used for this experiment were handled according to the rules and regulations for experimental animal management as stated in the Guide for the Care and Use of Laboratory Animals. This study was approved by the Institutional Office of Research and Development, Ekiti 
State University and an approval number ORD/AD/EAC/ $19 / 76$ assigned to the study.

\section{Experimental Animals, Induction of Inflammation and Treatment}

Forty-five Wistar strain rats $(100 \mathrm{~g})$ were obtained from the College of Medicine Animal House, Physiology Department, University of Ibadan and were acclimatized for a week, fed with water and rat chow ad libitum. Inflammation was intraperitoneally induced in twentyfive rats using a repeated dose of $5 \mathrm{mg} / \mathrm{kg}$ lipopolysaccharide (Sigma-Aldrich, Germany) dissolved in normal saline for three consecutive days. This dose was chosen as the most effective dose after a pilot study using 1,3 and $5 \mathrm{mg} /$ $\mathrm{kg}$. Inflammation was confirmed by determining the serum concentrations of IL- $1 \beta$, IL- 6 and TNF- $\alpha$ and comparing them with that of a normal control.

The animals were thereafter grouped $(n=5)$ as follows: group I, LPS negative control group (treated with $10 \mathrm{~mL} / \mathrm{kg}$ saline), group II, positive control group treated with $1 \mathrm{mg} / \mathrm{kg}$ ibuprofen as a non-steroidal anti-inflammatory drug, and groups III-V, 50, 100 and $200 \mathrm{mg} / \mathrm{kg}$ of the $n$-hexane fraction of $A$. boonei, respectively. In another experiment, twenty rats not induced with LPS, grouped into four groups $(n=5)$, were treated with the same dose of the fraction. The last group was treated with ibuprofen. A separate group of five rats designated normal control was given $10 \mathrm{~mL} / \mathrm{kg}$ of distilled water. Treatment lasted for 7 consecutive days via oral gavage. The doses of the $n$-hexane fraction of $A$. boonei used was based on the pilot study carried out prior to the main study. They were found to have the highest anti-inflammatory effect with minimal toxicity.

\section{Serum Preparation}

After treatment for seven days, the rats were sacrificed via cervical dislocation. Blood samples were collected from the heart, aspirated into plain sample bottles and allowed to clot. The clotted blood samples were thereafter spun at $5000 \mathrm{rpm}$ in a centrifuge (Sigma 300-K, Germany) at $10{ }^{\circ} \mathrm{C}$ for $5 \mathrm{~min}$. Serum was thereafter collected into clean sample bottles using a Pasteur pipette, stored at $10{ }^{\circ} \mathrm{C}$ and used within two days.

\section{Isolation of Mitochondria}

Liver mitochondria were isolated according to the method of Johnson and Lardy. ${ }^{29}$ Specifically, liver was excised and washed in insolation buffer $(210 \mathrm{mM}$ Mannitol, $70 \mathrm{mM}$ sucrose, $5 \mathrm{mM}$ Hepes-KOH (pH 7.4) and $1 \mathrm{mM}$ EGTA), until it was free from blood stains. It was later weighed (MP 1001 Electronic balance, China) chopped into bits and homogenized in a ten percent suspension of the isolation buffer using porter an Elvehjem homogenizer (USA) on ice. This was loaded into the centrifuge at $4{ }^{\circ} \mathrm{C}$ and spun at $2300 \mathrm{rpm}$ twice at five min each time to pellet unbroken cells and cell debris. The supernatant was further spun at 13,000 rpm for ten min to obtain mitochondria. Mitochondria were washed at 12,000 rpm with washing buffer (210 mM Mannitol, $70 \mathrm{mM}$ sucrose, $5 \mathrm{mM}$ Hepes$\mathrm{KOH}(\mathrm{pH} 7.4)$ and $0.5 \% \mathrm{BSA}$ ) for ten min and the pellet preserved on ice in aliquots using suspension buffer (210 $\mathrm{mM}$ Mannitol, $70 \mathrm{mM}$ sucrose, $5 \mathrm{mM}$ Hepes- $\mathrm{KOH}(\mathrm{pH}$ 7.4)). Isolation of mitochondria for the ATPase assays follows similar steps but $0.25 \mathrm{M}$ sucrose was used as a buffer.

\section{Determination of Mitochondrial Protein Content}

Since accurate mitochondrial permeability transition determination and assessment of mitochondrial $\mathrm{F}_{0} \mathrm{~F}_{1}$ ATPase activity depends on mitochondrial protein quantitation, mitochondrial protein content was estimated using the sensitive Lowry method. ${ }^{30}$ Mitochondria $(10 \mu \mathrm{L})$ were added to $990 \mu \mathrm{L}$ of distilled water in test tubes in triplicates. Thereafter, $3 \mathrm{~mL}$ of a 100:1:1 mixture of $2 \mathrm{~g}$ sodium potassium tartrate, $2 \mathrm{~g} \mathrm{Na}_{2} \mathrm{CO}_{3}$ in $0.1 \mathrm{M} \mathrm{NaOH}$, and $1 \%$ $\mathrm{CuSO}_{4} .5 \mathrm{H}_{2} \mathrm{O}$ (respectively) was added and the mixture was vortexed and allowed to stand for $10 \mathrm{~min}$ after which $0.3 \mathrm{~mL}$ of a 5 -fold dilution of $2 \mathrm{~N}$ Folin reagent was added and the whole mixture was incubated at room temperature for $30 \mathrm{~min}$, vortexed again and absorbance read at $750 \mathrm{~nm}$ with a 752 (N) UV-Visible spectrophotometer (BOSCH, China).

\section{Mitochondrial Permeability Transition Assay}

Inductive effects of inflammation on mitochondrial permeability transition and possible mitigating effects of the $n$-hexane fraction of $A$. boonei on the pore opening were assessed as per the previously described method. ${ }^{31}$ The suitability of the isolated mitochondria for this assay was first assessed as follows: mitochondria $(0.4 \mathrm{mg} / \mathrm{mL}$ protein) isolated from the normal control group were preincubated in suspension buffer $(210 \mathrm{mM}$ Mannitol, 70 
$\mathrm{mM}$ sucrose, $5 \mathrm{mM}$ Hepes- $\mathrm{KOH}$ (pH 7.4)) in the presence of $8 \mu \mathrm{M}$ rotenone for $3.5 \mathrm{~min}$ after which $5 \mathrm{mM}$ succinate was added to energize the medium and the absorbance read for $12 \mathrm{~min}$ at $30 \mathrm{sec}$ intervals. To assess the inductive effect of calcium, the same mitochondrial protein was preincubated in suspension buffer in the presence of rotenone for 3 min after which $3 \mu \mathrm{M} \mathrm{CaCl}_{2}$ was added. Thirty sec after, $5 \mathrm{mM}$ sodium succinate was added and absorbance read. To assess the reversal effect of spermine on the induced $\mathrm{mPT}$ by calcium, mitochondrial protein was preincubated in suspension buffer, rotenone and $4 \mathrm{mM}$ spermine for 3 min after which $3 \mu \mathrm{M} \mathrm{CaCl}_{2}$ was added. Thirty sec after, the medium was energized with succinate and the absorbance read at $540 \mathrm{~nm}$ using a spectrophotometer. Isolated mitochondria with negligible induction of $\mathrm{mPT}$ in the absence of calcium, large amplitude induction in the presence of calcium and nearly normal reversal of the induced $\mathrm{mPT}$ by spermine is adjudged uncoupled and therefore suitable for the assays. Equivalent mitochondrial proteins from the treated groups were subjected to the same permeability transition under the same condition.

\section{Determination of Mitochondrial $\mathrm{F}_{0} \mathrm{~F}_{\mathrm{I}}$ ATPase Activity}

To fully understand the effects of inflammation in the hepatocytes on ATP metabolism, mitochondrial $\mathrm{F}_{0} \mathrm{~F}_{1}$ ATPase activity was determined using the established method of Lardy and Wellman with slight modification. ${ }^{32}$ Briefly, $25 \mathrm{mM}$ sucrose and $65 \mathrm{mM}$ Tris- $\mathrm{HCl}(\mathrm{pH} 7.4)$ were added to $0.5 \mathrm{mM} \mathrm{KCl}$ in a test tube and the reaction volume was made up to $1 \mathrm{~mL}$. Disodium salt of ATP (1 $\mathrm{mM}$ ) was added to the tubes and transferred to the shaking water bath and incubated at $27{ }^{\circ} \mathrm{C}$. Mitochondria $(0.5 \mathrm{mg} /$ $\mathrm{mL}$ protein) were added to the designated tubes while tubes designated mitochondria only and ATP only were used to monitor isolated mitochondrial integrity and hydrolysis of ATP prior to the assay. The uncoupler and zero time tubes contained mitochondria isolated from the normal control group. Uncoupler $(25 \mu \mathrm{M}$ of 2,4-dinitrophenol) was added to the uncoupler tubes immediately after mitochondria were added and $1 \mathrm{~mL}$ of $10 \%$ sodium duodecylsulphate (SDS) was immediately added to the zero-time test tubes. The mixtures were incubated for 30 min after which the reaction was stopped in all the tubes except the zero time test tubes with $1 \mathrm{~mL}$ SDS. The test tubes were taken out and $1 \mathrm{~mL}$ was withdrawn from each test tube. These were diluted further with $4 \mathrm{~mL}$ distilled water. One $\mathrm{mL}$ of $1.25 \%$ ammonium molybdate (prepared in $6.5 \% \mathrm{H}_{2} \mathrm{SO}_{4}$ ) and $1 \mathrm{~mL}$ of $9 \%$ freshly prepared ascorbic acid were added in quick succession and the absorbance was read at $660 \mathrm{~nm}$ in a spectrophotometer. Inorganic phosphate released was quantified from a phosphate standard curve.

\section{Assay of Inflammatory Cytokines}

ELISA kits for IL-1 $\beta$ and IL-6, obtained from Elabscience, USA were used to assay for serum IL- $1 \beta$ and IL- 6 by strictly following the manufacturer's protocol. Serum levels of TNF- $\alpha$ and CRP were determined by using ELISA assay kits also from Elabscience, USA by following the manufacturer's protocol using a DNM-9602A microplate reader.

\section{Determination of Aspartate and Alanine Aminotransferases and Gamma Glutamyl Transferase Activities}

Serum aspartate and alanine aminotransferases (AST and ALT, respectively) levels were determined by using ELISA assay kits (from MTD diagnostics, Italy), and gamma glutamyl transferase (GGT) levels were determined by using ELISA assay kits (Fortress diagnostics, UK) strictly following the manufacturer's protocol.

\section{Chemical Profiling of the $n$-Hexane Fraction of Alstonia boonei}

Analysis of phytochemicals in the $n$-hexane fraction of Alstonia boonei was carried out using a Waters UPLC coupled in series to a Waters SYNAPT G1 HDMS mass spectrometer to generate full-scan accurate mass data. Optimization of the chromatographic separation was done utilizing a Waters HSS T3 C18 column $(150 \mathrm{~mm}$ $\mathrm{x} 2.1 \mathrm{~mm}, 1.8 \mu \mathrm{m})$ and the column temperature controlled at $60{ }^{\circ} \mathrm{C}$. Methanol and acetonitrile were evaluated as organic modifiers with acetonitrile producing the best chromatographic peak shape. A binary solvent mixture was used consisting of water (Eluent A) containing 10 $\mathrm{mM}$ formic acid (natural $\mathrm{pH}$ of 2.4) and acetonitrile (Eluent B) containing $10 \mathrm{mM}$ formic acid. The initial conditions were $98 \% \mathrm{~A}$ at a flow rate of $0.4 \mathrm{~mL} / \mathrm{min}$ and were maintained for $1 \mathrm{~min}$, followed by a linear gradient to 2\% A at $16 \mathrm{~min}$. The conditions were kept constant for $1 \mathrm{~min}$ and then changed to the initial conditions. The runtime was 20 min and the injection volume was $2 \mu \mathrm{L}$. 
Samples were kept cool at $8{ }^{\circ} \mathrm{C}$ in the Waters Sample Manager during the analysis.

The SYNAPT G1 mass spectrometer was used in V-optics and operated in electrospray mode to enable detection of all ESI-compatible compounds. Leucine enkephalin $(50 \mathrm{pg} / \mathrm{mL})$ was used as reference calibrant (Lock Mass) to obtain typical mass accuracies between 1 and 5 mDalton $(\mathrm{mDa})$. The mass spectrometer was operated in both ESI positive and negative modes with a capillary voltage of $2.5 \mathrm{kV}$, the sampling cone at $30 \mathrm{~V}$ and the extraction cone at $4.5 \mathrm{~V}$. The scan time was $0.1 \mathrm{sec}$ covering the 50 to 1000 Dalton mass range with an interscan time of $0.02 \mathrm{sec}$. The source temperature was $120^{\circ} \mathrm{C}$ and the desolvation temperature was set at $450{ }^{\circ} \mathrm{C}$. Nitrogen gas was used as the nebulisation gas at a flow rate of 550 $\mathrm{L} / \mathrm{h}$ and cone gas was added at $50 \mathrm{~L} / \mathrm{h}$. The software used to control the hyphenated system and do all data manipulation was MassLynx 4.1 (SCN 872).

Compound identification was further enhanced by analyzing all samples with low and high collision energy settings of the collision cell. To minimize compound fragmentation a low energy setting of $3 \mathrm{eV}$ was used, but to enhance fragmentation of molecules a collision energy ramp of 10-40 eV was used. Argon was used as collision gas in the collision cell.

\section{Statistical Analysis}

Representative profiles of absorbance of mitochondria were used for mitochondrial permeability transition pore induction assays. Other data were analyzed using descriptive statistics on duplicates (mean \pm standard deviation). They were further analyzed by comparing the normal control data with test groups using one-way analysis of variance. GraphPad prism (7.0 version) was used and Tukey's post hoc comparison method was used to compare means among columns.

\section{Results}

\section{Mitochondrial Pore Opened in Response to Induced Inflammation and Was}

Reversed by $n$-Hexane Fraction of $A$. boonei

In order to understand the effects of inflammation on cellular metabolism especially in actively respiring organelle like mitochondrion and the possible influence of an anti-inflammatory drug, we assayed for the effects of the drug and inflammation on this organelle via m|PT. Lipopolysaccharide opens the $\mathrm{mPT}$ pore by 15 folds compared to the control at $5 \mathrm{mg} / \mathrm{kg}$
(Figure 1A). These effects were reduced to 6 folds when ibuprofen was used to treat inflammation while this drug opens the mitochondrial pore to the tune of 5 folds in noninflammatory mitochondria (Figure 1B). Furthermore, we observed that the influence of the standard drug $(1 \mathrm{mg} / \mathrm{kg})$ on mPT when administered only to rats in which inflammation was not induced was similar to when it was used to treat lipopolysaccharide-induced inflammation in the liver (Figure 1B). In contrast, the $n$-hexane fraction of $A$. boonei has minimal pore opening effects in non-inflammatory mitochondria (2 folds) when compared with the standard drug (Figure 1C). Again, it was observed that when $n$-hexane fraction of $A$. boonei was used to treat inflammation, the mitochondrial pore opening effect was reduced from 15 to 4 folds (Figure 1C).

\section{$n$-Hexane Fraction of $A$. boonei Reverses ATPase Activity}

To understand the effect of LPS on mitochondrial energy metabolism, enhancement of ATPase activity was determined. It was observed that the anti-inflammatory drug, when administered in the absence of lipopolysaccharide, enhanced $\mathrm{F}_{0} \mathrm{~F}_{1}$ ATPase activity $(P<0.01)$ similar to what was observed in the presence of the inducer (lipopolysaccharide) when compared with the normal control (Figure 2A). LPS enhanced $\mathrm{F}_{0} \mathrm{~F}_{1}$ ATPase activity (Figure 2B). The $n$-hexane fraction of $A$. boone i significantly decreased enhancement of ATPase activity at $50 \mathrm{mg} / \mathrm{kg}(P<$ $0.05)$ and further at $100 \mathrm{mg} / \mathrm{kg}(P<0.01)$ in the absence of LPS (Figure 2C) while the effect of this fraction at $200 \mathrm{mg} / \mathrm{kg}$ was not significantly different when compared with LPS control. Interestingly, similar effects were noticed when the $n$-hexane fraction of $A$. boone $i$ was used to treat LPS-induced inflammation in rats (Figure 2C) meaning that the $100 \mathrm{mg} / \mathrm{kg}$ of $A$. boonei significantly reversed the activity of the enzyme in LPS-induced inflammation as observed in this study.

\section{$n$-Hexane Fraction of $A$. boonei Inhibits IL- I $\beta$ and IL-6 Levels in Lipopolysaccharide- Induced Inflammation}

The effects of the $n$-hexane fraction of $A$. boonei on serum levels of inflammatory cytokines such as IL-1 $\beta$ and IL-6 were determined and the results are presented in Figure 3. It was observed that LPS significantly increased these cytokines. It was also observed that the non-steroidal anti-inflammatory drug (NSAIDS) (ibuprofen) used as drug control significantly $(P<0.05)$ decreased the levels of 

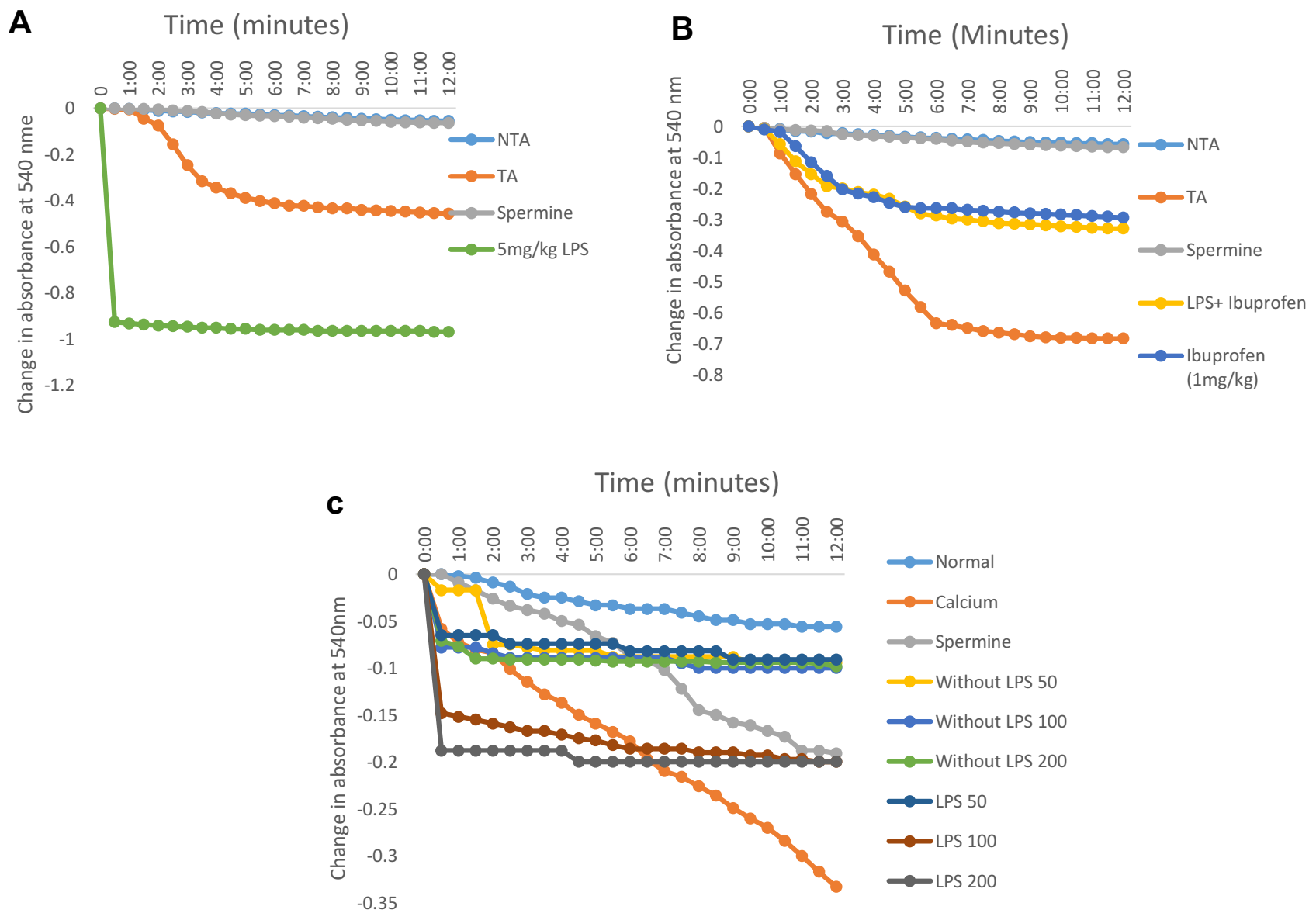

Figure I Representative profile of the changes in the absorbance of mitochondria isolated from rats treated with: graded doses of lipopolysaccharide to induce inflammation in the liver (A), ibuprofen as an anti-inflammatory drugn (B), and graded doses of the $n$-hexane fraction of $A$. boonei (C).

these pro-inflammatory cytokines (Figure $3 \mathrm{~A}$ and $\mathrm{B}$ ) and there was no significant difference in the effects when the NSAIDS was administered only and when it was administered to LPS-treated rats. It was observed also that graded doses of the $n$-hexane fraction of $A$. boonei decreased the level of IL-1 $\beta$ (Figure 3A). Although, $50 \mathrm{mg} / \mathrm{kg}$ of the fraction significantly $(P<0.0001)$ decreased the level of IL-1 $\beta$ and $200 \mathrm{mg} / \mathrm{kg}$ of the fraction increased the level of this cytokine, no significant difference between the IL-1 $\beta$ level in normal control and rats treated with $100 \mathrm{mg} / \mathrm{kg}$ of the fraction was observed. Similar effects were noticed in the level of IL- 6 and there was no significant difference between the normal control and the treated groups (Figure 3B).

\section{$n$-Hexane Fraction of A. boonei Decreases Circulating Concentrations of TNF- $\alpha$, CRP and CK in Rats}

In addition to the effects of the $n$-hexane fraction of $A$. boone on interleukins $1 \beta$ and 6 in LPS-induced inflammation, the effects of this fraction on serum levels of TNF- $\alpha$, CRP and activities of $\mathrm{CK}$ in rats were determined and the results are presented in Figure 4. It was observed that there was a significant decrease $(P<0.0001)$ in the levels of TNF- $\alpha$ in all the treated groups relative to the negative control. It was also observed that although all the doses significantly decreased the level of TNF- $\alpha$, the effect of the fraction did not vary linearly with the dose and maximum effect was observed at the $100 \mathrm{mg} / \mathrm{kg}$ dose (Figure 4A). Similarly, it was observed that ibuprofen significantly $(P<0.0001)$ decreased TNF- $\alpha$ level in rats where LPS was not administered when compared with its mitigating effects in LPStreated rats and there was no significant difference between the levels of TNF- $\alpha$ in normal rats not treated with ibuprofen and normal, ibuprofen-treated rats.

Furthermore, it was observed that CK activity in the rats treated with LPS only (negative control) increased but was significantly decreased with the $n$-hexane fraction of $A$. boone $i$ intervention. No significant difference was observed between the activity of CK in the normal control and the graded doses of 


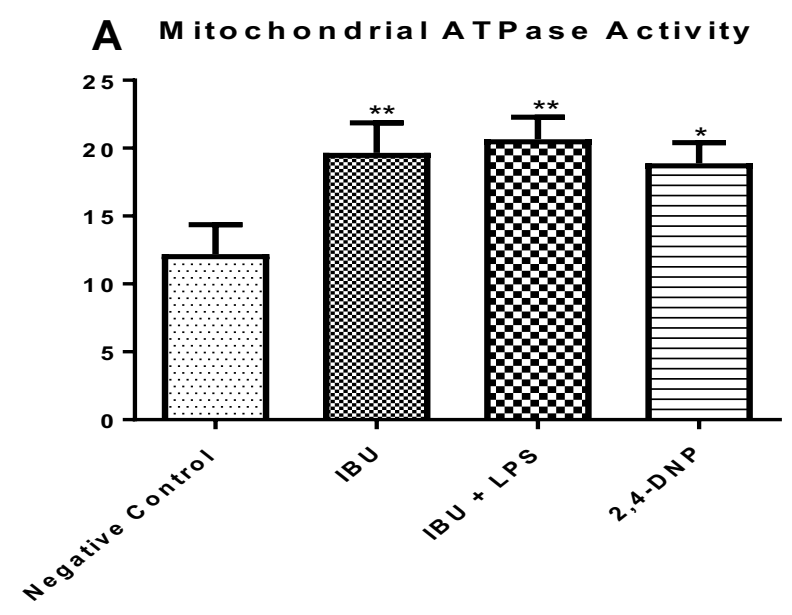

B

Mitochondrial A TPase Activity

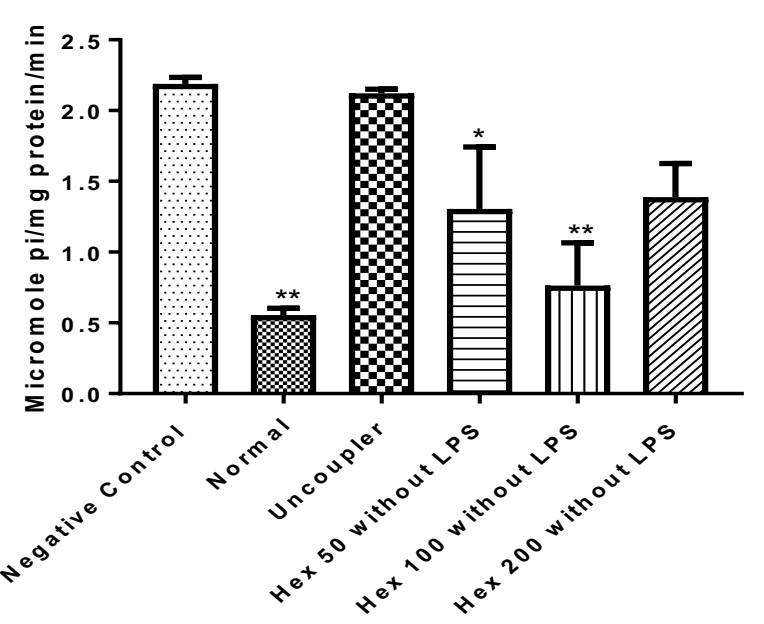

C M itochondrial A T Pase Activity

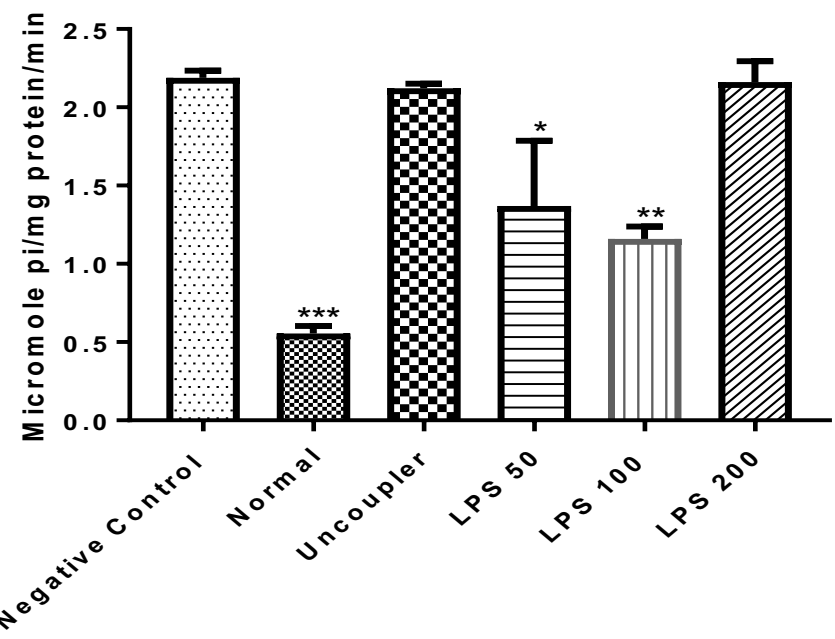

Figure 2 Influence of the $n$-hexane fraction of $A$. boonei on $F_{0} F_{1}$ ATPase activity in lipopolysaccharide-induced hepatic inflammation in rats. $* P<0.05$; $* * P<0.01 ; * * * P<0.001$ LPS control versus test groups.

A. boonei fraction. While $100 \mathrm{mg} / \mathrm{kg}$ dose of the fraction significantly $(P<0.05)$ decreased the CK level compared with the $50 \mathrm{mg} / \mathrm{kg}$ dose, there was no significant difference between the effects of the 100 and $200 \mathrm{mg} / \mathrm{kg}$ doses on CK activity in LPS-treated rats (Figure 4B). However, it is interesting to note that ibuprofen treatments both in LPS-induced inflammation and normal rats significantly $(P<0.05$ and $P<$ 0.01 , respectively) increased CK activity.

Assay of the C-reactive protein (CRP) level in this study showed that LPS administration increased the serum level of this protein while the administration of the fraction, especially the $50 \mathrm{mg} / \mathrm{kg}$ dose significantly $(P<0.05)$ decreased it. However, it was observed that 100 and $200 \mathrm{mg} / \mathrm{kg}$ dose did not elicit any significant difference in the level of this protein when compared with the negative (LPS only) control. As observed previously, administration of ibuprofen significantly lowered CRP level in rats challenged with LPS and the level of this protein was further lowered (significantly) when ibuprofen was administered in the absence of LPS (Figure 4C).

\section{Hepato-Toxic Effects of Lipopolysaccharide, Potentiated by Ibuprofen Was Mitigated by the $n$-Hexane Fraction of $A$. boonei}

To understand the hepatotoxic effects of lipopolysaccharide and the potentiating effects of this toxicity by 

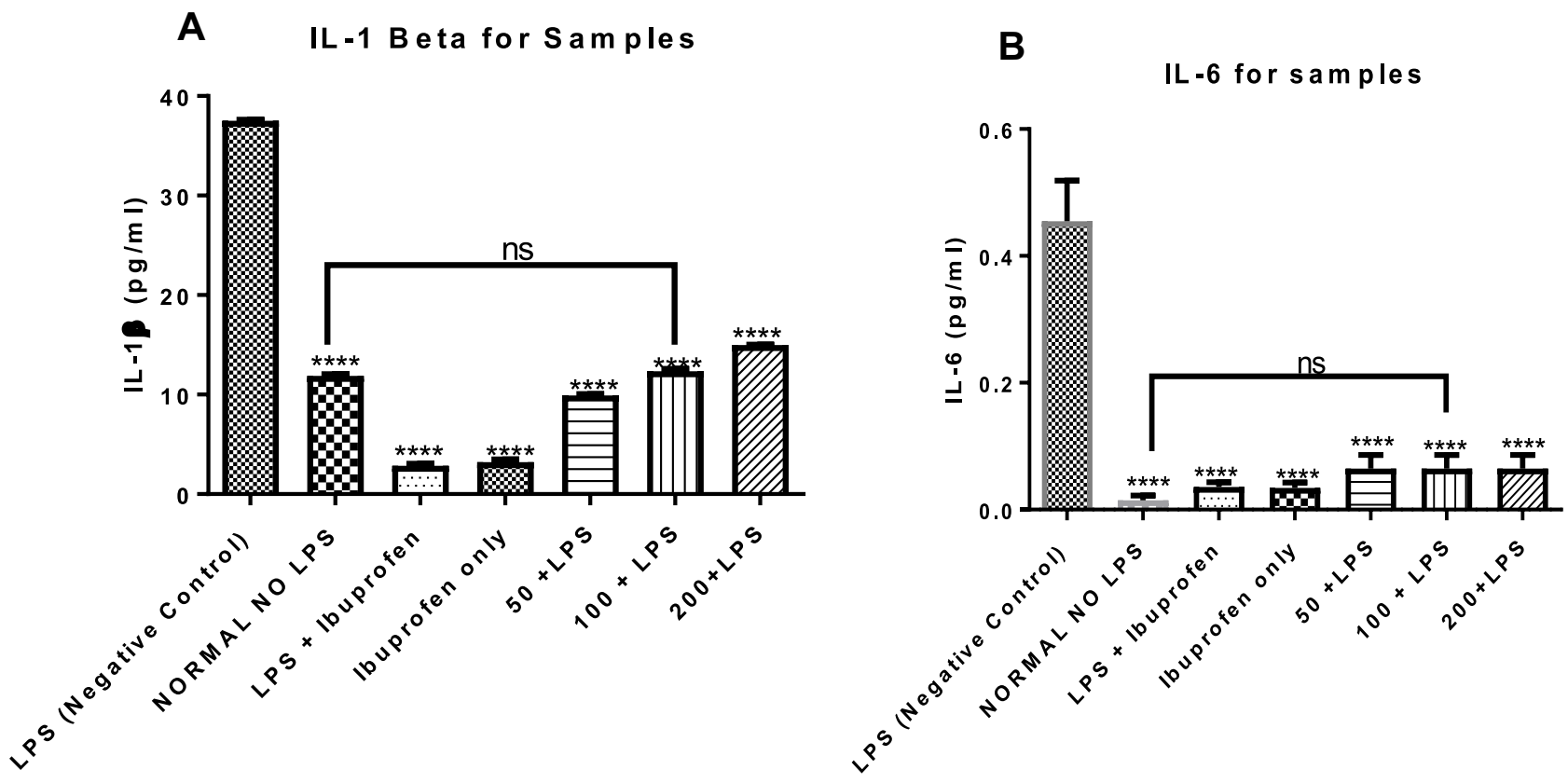

Figure 3 Mitigating effects of the $n$-hexane fraction of $A$. boonei on increase in interleukin I beta $(\mathbf{A})$ and interleukin 6 (B) induced by lipopolysaccharide. Where ns= not significant; $* * * *=P<0.000$ I LPS control versus test groups.

ibuprofen treatment, marker enzymes for hepatic lesions such as aspartate and alanine aminotransferases (AST and ALT, respectively) and gamma glutamyl transferase (GGT) were assayed for in the serum of rats to which lipopolysaccharide and ibuprofen were separately administered. It was observed that LPS administration increased the activity of AST $(P<0.01)$ when compared to the activity of this enzyme in rats that were not induced with LPS but treated with distilled water only (normal control). It was observed that when ibuprofen was administered to treat inflammation, serum activity of AST in rats treated with ibuprofen increased $(P<0.01)$ compared to the LPS control while administration of ibuprofen only increased $(P<0.01)$ serum AST activity. This effect was mitigated by graded doses of the $n$-hexane fraction of $A$. boone (Figure 5A).

Lipopolysaccharide further increased the activity of ALT compared to the normal control $(P<0.05)$ while the activity of this enzyme was further decreased in rats induced with LPS but treated with ibuprofen $(P<0.01)$. Furthermore, there was no significant difference in the activity of ALT in rats treated with LPS only and those that were treated with ibuprofen. On the contrary, the $n$-hexane fraction of $A$. boonei further decreased the activity of this enzyme when used to treat LPS-induced inflammation (Figure 5B). The activity of GGT in rats that received LPS only increased when compared with the normal control. However, rats treated with ibuprofen only showed more significant increases in the activity of this enzyme (Figure 5C).

\section{Chemical Profile of the $n$-Hexane \\ Fraction of Alstonia boonei}

Phytochemicals corresponding to the chromatographic peaks in the $n$-hexane fraction of $A$. boonei (Figure 6) were determined by full-scan MS and MS/MS analysis using both the positive and negative-ion mode based on their accurate mass, and fragment ions in comparison with those available on the Mass Bank and SciFinder ${ }^{\mathbb{B}}$ databases and of data reported in literature. Fifteen compounds were identified from the $n$-hexane fraction of $A$. boonei, amongst which is a macro-cyclic lactone (1), lipids (2, 5 and 8) and sphingolipids (7 and 9). Two phenolic compounds (3 and 4), three phytosterols $(6,10$ and 12$)$ and a 6 '-prenylated sterol glycoside (15) were also identified. The result of the UHPLC-MS is presented in Table 1 while the structural diversity in the identified compounds is shown in Figure 6.

\section{Discussion}

There has been substantial evidence that terpenes from medicinal plants have anti-inflammatory properties and A. boonei is folklorically used for the treatment of inflammation. The $n$-hexane fraction of $A$. boonei justifies this 

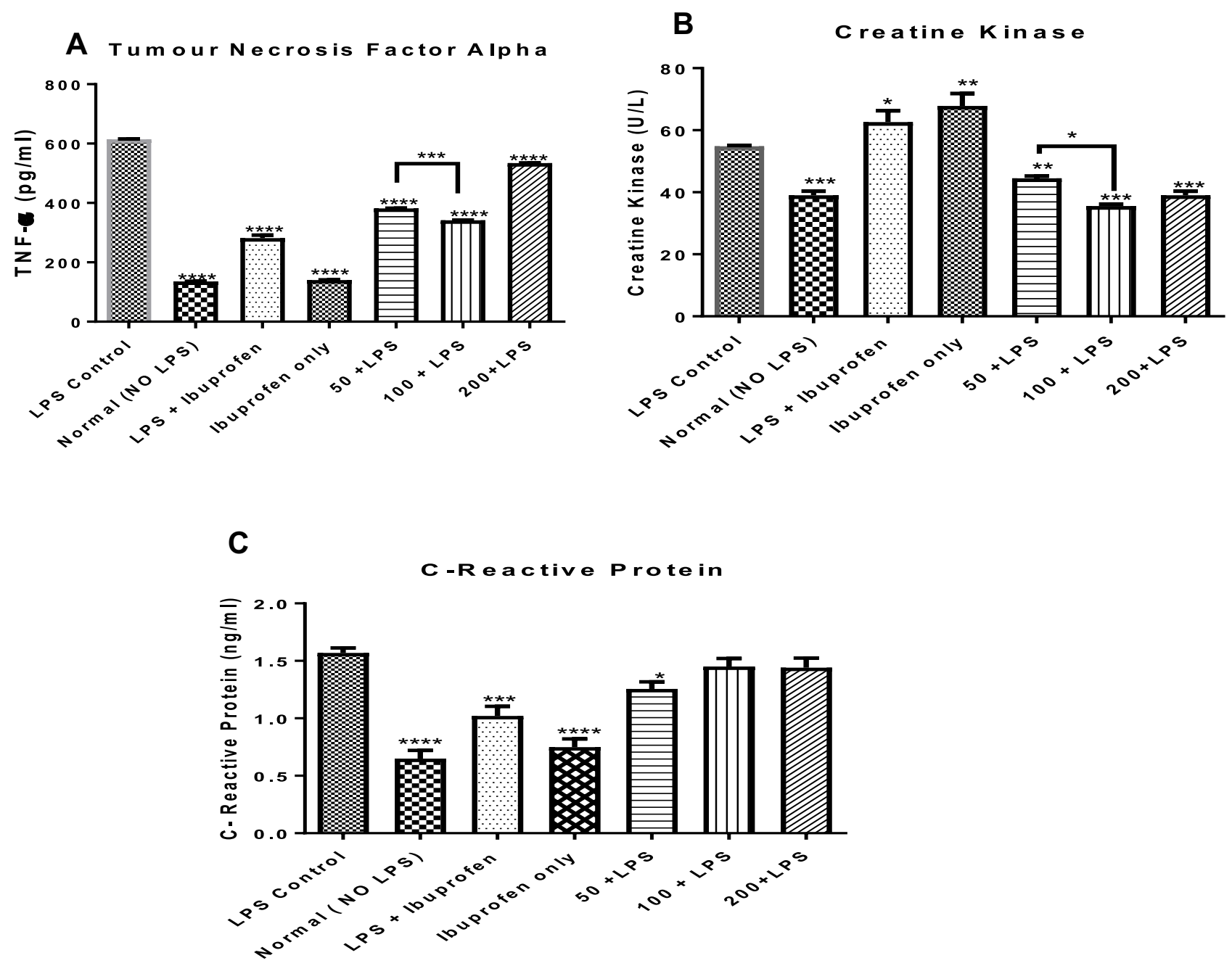

Figure 4 Effects of the administration of the $n$-hexane fraction of $A$. boonei to rats challenged with lipopolysaccharide on TNF- $\alpha(\mathbf{A})$, creatine kinase (B) and C-reactive protein (C). ${ }^{*} P<0.05 ; * * P<0.01$; $* * * P<0.001$; $* * * P<0.000$ I LPS control versus test groups.

dual position and is therefore, worthy of being researched into given the fact that $A$. boone $i$ is a good medicinal plant of choice for this purpose. This study, therefore, was conducted to examine the plant's mitigating effects on liver inflammation via its reversal effect on mitochondrial permeability transition, restoration of mitochondrial $\mathrm{F}_{0} \mathrm{~F}_{1}$ ATPase energy-generating role and reduction in proinflammatory biomarkers. The results of this study reveal an increase in large amplitude swelling of mitochondria, significant enhancement of mitochondrial $\mathrm{F}_{0} \mathrm{~F}_{1}$ ATPase activity and increase in the activities of markers of liver toxicity in response to lipopolysaccharide administration, and the restorative role of the $n$-hexane fraction of A. boonei on related damages in LPS-treated rats in comparison with the negative control.

The results of this study show that indeed, induction of $\mathrm{mPT}$ is one of the pro-inflammatory roles of LPS in the liver observed in this case as a decrease in the changes in the absorbance of liver mitochondria isolated from rats treated with LPS only. It is possible that LPS might have caused this opening of the $\mathrm{mPT}$ pore via free radical generation. This result may also suggest that free radicals could have caused the peroxidation of the outer mitochondrial membrane lipids causing the permeabilization of the mitochondrial outer membrane. This damage caused by free radicals could cause the opening of the $\mathrm{MPT}$ pore, rendering the membrane leaky to macromolecules. It is also possible that the generation of free radicals by LPS could cause changes in the conformation of the mitochondrial pore components or possibly causing the mitochondrial proteins to unfold and be denatured. ${ }^{33-35}$ Furthermore, the mitochondrion is the energy generating plant for the cell and in this process, superoxide anions are generated as free radical components. This means that 


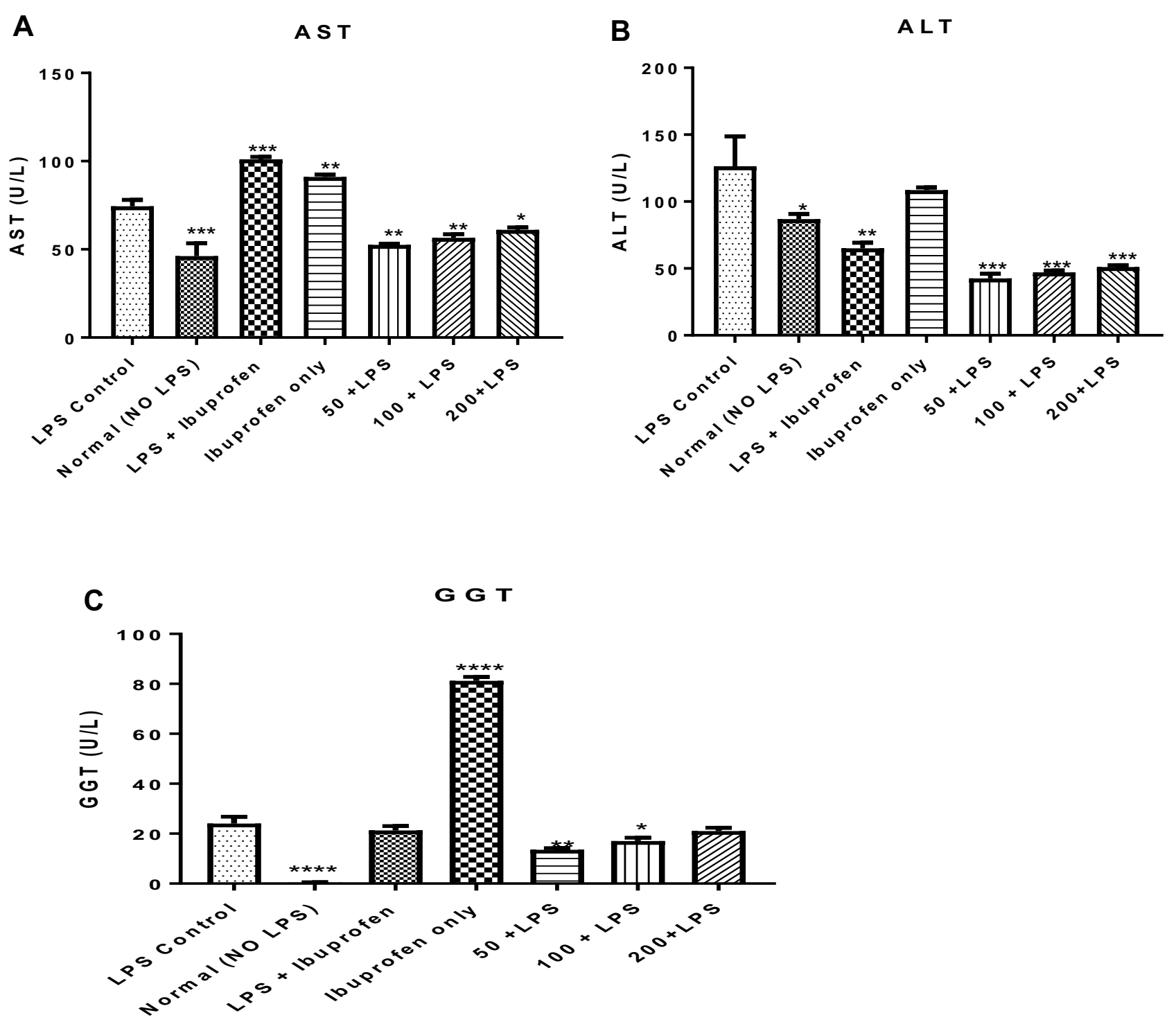

Figure 5 Mitigating effect of the $n$-hexane fraction of Alstonia boonei on hepatotoxic effects of lipopolysaccharide using aspartate (A) and alanine (B) aminotransferases as well as gamma glutamyl transferase (C). $* P<0.05 ; * * P<0.01$; $* * * P<0.001$; $* * * * P<0.0001$ treated groups vs lipopolysaccharide negative control.

while performing its functional roles in the cell, mitochondria generate free radicals sufficient for its oxidative damage. Therefore, exogenous source of free radical through LPS administration is practically lethal for the existence of this organelle and by extension the entire cell.

The observation that phytochemical components of the $n$-hexane fraction reversed $\mathrm{mPT}$ in liver mitochondria could be as a result of the antioxidant effect of such phytochemicals, mopping up the free radicals or functioning as a proton donor neutralizing the oxidative, damaging effects of free radicals generated by LPS and those generated by mitochondria during its respiratory role. Furthermore, it is interesting to note that administration of the $n$-hexane fraction only did not have a pore opening effect on the isolated liver mitochondria showing that it is safe for the mitochondria at the dose administered. It has been observed in this study that administration of ibuprofen only to rats that were not pre-treated with LPS caused the opening of the pore and there was not any difference between this set of rats and those in which inflammation was induced with LPS and were subsequently treated with ibuprofen $(1 \mathrm{mg} / \mathrm{kg})$. The fatality recorded when rats were treated with ibuprofen shows that although this standard drug may provide remediation primarily from the immediate need for the treatment of inflammation, some underlying secondary adverse effect may necessitate the consideration for its use. Interestingly, previous studies have provided evidence that ibuprofen causes 


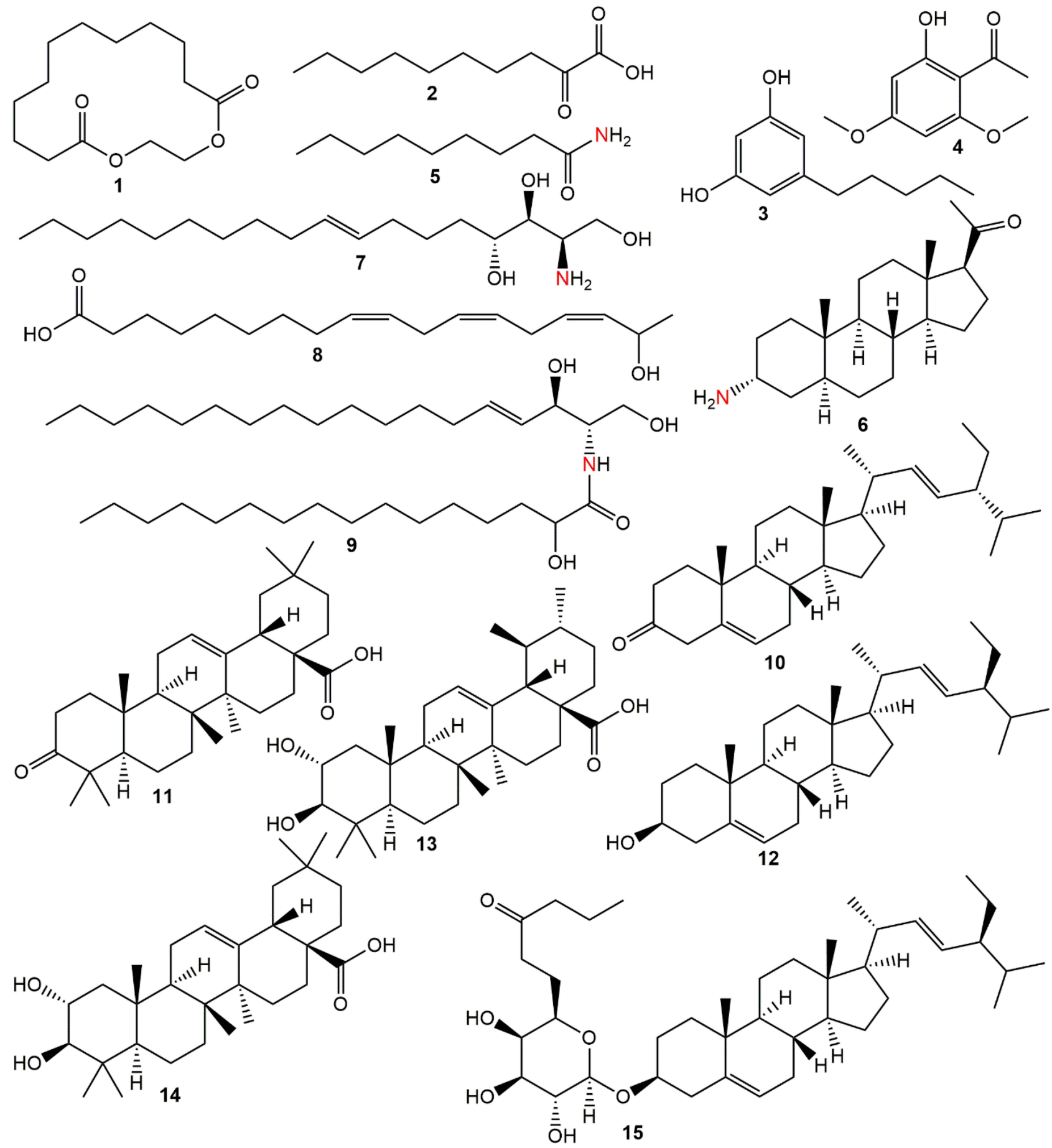

Figure 6 Phytochemicals identified in the $n$-hexane fraction of $A$. boonei.

mitochondrial dysfunction by inducing the release of cytochrome $\mathrm{c}$ into the cytosol, thus causing apoptosis and unselective mPT pore opening. ${ }^{36}$

The characteristic features of an $\mathrm{mPT}$ opening includes cytochrome $c$ release, enhancement of $\mathrm{F}_{0} \mathrm{~F}_{1}$ ATPase activity, and decrease in mitochondrial membrane potential. The mitochondrial $F_{0} F_{1}$ ATPase is a bi-directional enzyme that synthesizes ATP when there is an increase in the mitochondrial membrane potential and to overcome this critical challenge, this enzyme hydrolyzes ATP (as an ATPase) to maintain the mitochondrial membrane potential. This action alone increases the concentration of the cytosolic inorganic phosphate ( $\mathrm{Pi}$ ) which, incidentally, is an inducer of the opening of the $\mathrm{mPT}$ pore. Therefore, it 
Table I UHPLC-MS Report of the $n$-Hexane Fraction of $A$. boonei

\begin{tabular}{|c|c|c|c|c|c|c|}
\hline Peak & tR (Min) & Compound & Formula & DBE & Found Mass (m/z) & Adduct \\
\hline 1 & 7.71 & I,4-Dioxacyclohexadecane-5, I6-dione & $\mathrm{C}_{14} \mathrm{H}_{24} \mathrm{O}_{4}$ & 3 & 257.1679 & {$[\mathrm{M}+\mathrm{H}]^{+}$} \\
\hline 2 & 8.22 & 2-Oxodecanoic acid & $\mathrm{C}_{10} \mathrm{H}_{18} \mathrm{O}_{3}$ & 2 & 187.1276 & {$[\mathrm{M}+\mathrm{H}]^{+}$} \\
\hline 3 & 8.81 & Olivetol & $\mathrm{C}_{11} \mathrm{H}_{16} \mathrm{O}_{2}$ & 4 & 181.1259 & {$[\mathrm{M}+\mathrm{H}]^{+}$} \\
\hline 4 & 9.00 & Xanthoxylin & $\mathrm{C}_{10} \mathrm{H}_{12} \mathrm{O}_{4}$ & 5 & 195.0575 & {$[\mathrm{M}-\mathrm{H}]^{-}$} \\
\hline 5 & 9.24 & Nonanamide & $\mathrm{C}_{9} \mathrm{H}_{19} \mathrm{NO}$ & I & $|58.158|$ & {$[\mathrm{M}+\mathrm{H}]^{+}$} \\
\hline 6 & 9.49 & Funtumine & $\mathrm{C}_{21} \mathrm{H}_{34} \mathrm{NO}$ & 5 & $3|8.276|$ & {$[\mathrm{M}+\mathrm{H}]^{+}$} \\
\hline 7 & 10.21 & Dehydrophytosphingosine & $\mathrm{C}_{18} \mathrm{H}_{37} \mathrm{NO}_{3}$ & I & 316.2853 & {$[\mathrm{M}+\mathrm{H}]^{+}$} \\
\hline 8 & 12.52 & I7-Hydroxylinolenic acid & $\mathrm{C}_{18} \mathrm{H}_{30} \mathrm{O}_{3}$ & 4 & 293.2105 & {$[\mathrm{M}-\mathrm{H}]^{-}$} \\
\hline 9 & |3.7| & $\mathrm{N}-2$-Hydroxypalmitoylsphingosine & $\mathrm{C}_{34} \mathrm{H}_{67} \mathrm{NO}_{4}$ & 2 & 554.5114 & {$[\mathrm{M}+\mathrm{H}]^{+}$} \\
\hline 10 & 14.53 & Stigmasterone & $\mathrm{C}_{29} \mathrm{H}_{46} \mathrm{O}$ & 7 & 411.3642 & {$[\mathrm{M}+\mathrm{H}]^{+}$} \\
\hline 11 & 15.62 & Oleanonic acid & $\mathrm{C}_{30} \mathrm{H}_{46} \mathrm{O}_{3}$ & 8 & 453.3339 & {$[\mathrm{M}-\mathrm{H}]^{-}$} \\
\hline 12 & 16.56 & Stigmasterol & $\mathrm{C}_{29} \mathrm{H}_{48} \mathrm{O}$ & 6 & 413.3752 & {$[\mathrm{M}+\mathrm{H}]^{+}$} \\
\hline 13 & 16.59 & Corosolic acid & $\mathrm{C}_{30} \mathrm{H}_{48} \mathrm{O}_{4}$ & 7 & 471.3477 & {$[\mathrm{M}-\mathrm{H}]-$} \\
\hline 14 & 16.95 & Maslinic acid & $\mathrm{C}_{30} \mathrm{H}_{48} \mathrm{O}_{4}$ & 7 & 471.3450 & {$[\mathrm{M}-\mathrm{H}]-$} \\
\hline 15 & 17.16 & $\beta$-D-Galactopyranoside, (3ß)-stigmast-5-en-3-yl, 6-butanoate & $\mathrm{C}_{39} \mathrm{H}_{66} \mathrm{O}_{7}$ & 7 & 647.4896 & {$[\mathrm{M}+\mathrm{H}]+$} \\
\hline
\end{tabular}

follows then that enhancement of the ATPase activity of this enzyme (acting in the reverse mode) would further cause an irreversible opening of the pore. The observation in this study that ibuprofen administration in rats that were not challenged with LPS caused enhancement of the ATPase activity, similar to what was observed when the drug was used to treat LPS-induced inflammation shows that indeed, mitochondrial ATPase activity is enhanced in both cases. Although the phytochemical components of the $n$-hexane fraction of $A$. boonei decrease ATPase activity maximally at $100 \mathrm{mg} / \mathrm{kg}$, an observation that treatment of LPS-induced inflammation with $200 \mathrm{mg} / \mathrm{kg}$ causes an increase in the activity of this enzyme indicates that administration of this fraction at such a high dose may not be profitable to prevent mitochondrial-mediated cell death. Previous reports by Mingatto et al corroborate the findings in this study that non-steroidal anti-inflammatory drugs interfere with oxidative phosphorylation and disrupt mitochondrial respiration to synthesize ATP. ${ }^{37}$

Interleukins $1 \beta$ (IL-1 $\beta$ ), interleukin-6 (IL-6), tumour necrosis factor alpha (TNF- $\alpha$ ) and C-reactive protein (CRP) are critical biomarkers for inflammation. Although the functions of each of these proteins are spelt out clearly, their synthesis and inflammatory roles are sometimes interdependent. ${ }^{38-41}$ For example, IL-6 production can be initiated by other cytokines such as TNF while IL-6 can act on the hepatocytes to initiate the production of CRP. The levels of these inflammatory biomarkers were determined only in LPS-induced inflammation experiments, only because it is here that inflammation was more pronounced and the results showed that indeed, the $n$-hexane fraction of $A$. boonei reduced the levels of these biomarkers as did NSAID. The observation in this study showed that the fraction can minimize pain, because of the significant reduction in the levels of IL- $1 \beta$, IL- 6 and TNF$\alpha$ that are involved in the process of pathological pain. Certain phytochemical(s) present in the $n$-hexane fraction of $A$. boonei might have unselectively and reversibly inhibit cyclooxygenases 1 and 2 as its mechanism of action, thus preventing other downstream events in inflammation. Depending on their structure-function relationship, these phytochemicals may also interact with opioid receptors, thus closing the voltage-gated calcium channels and opening calcium-dependent potassium channels. ${ }^{42}$ The resultant hyperpolarization and a reduction in neuronal excitability reduces pain and other associated effects of inflammation. Previous studies have shown the various mechanisms of action of phytochemicals possessing antiinflammatory potentials. ${ }^{43}$ This include: antioxidative and radical scavenging potential, modulation of the secretion of inflammation-related macromolecules, modulation of the activities of enzymes whose activities directly relate to inflammation such as phospholipases, cyclo-oxygenases, nitric oxide synthases and others. Phytochemicals can also regulate the expression of genes that produce some of the macromolecules involved in inflammation. It is also possible that anti-inflammatory phytochemicals may regulate two or more of these pathways at the same time. 
The appearance of creatine kinase in the blood is a signal for muscle damage and a critical sign for muscular dystrophy and myocardial infarction. ${ }^{44}$ Found in skeletal muscle and heart, a higher than normal level of creatine kinase indicates skeletal or cardiac muscle injury. It was observed in this study that ibuprofen, when used for the treatment of LPS-induced inflammation or when taken only, increased serum creatine kinase activity. Fraga et al found similar effects of ibuprofen on creatine kinase in paralympic athletes. ${ }^{45}$ Studies have shown that high doses of lipopolysaccharide can cause oxidative stress and that reactive oxygen species generated by lipopolysaccharide is the origin of injury and toxicity elicited by this macromolecule. $^{46}$ Exposure of hepatocytes to reactive oxygen species is capable of causing damage to the plasma membrane causing the leakage of cellular content such as proteins and enzymes into the extracellular surroundings. This leads to an increase in the plasma or serum activities of aminotransferases and instability in the cell membrane.

This study showed an increase in the activities of this aminotransferase despite ibuprofen administration in LPSinduced inflammation, indicating that the standard drug could not reverse the effect of LPS within this period to near normal as the $n$-hexane fraction of $A$. boone $i$ did. It was also observed that ibuprofen only causes an increase in AST, ALT and GGT, which indicates that this drug should be taken with caution as suggested by previous studies. ${ }^{47}$

Biochemical processes involved in inflammation and immunity are complex and only in the last few decades are their associated mechanisms being unraveled. Corticosteroids and other steroid-based drugs are currently used in inflammation therapies. ${ }^{48}$ However, severity of their side effects calls for alternatives with similar or better therapeutic potential having mild or no side effect. ${ }^{49}$ This balanced biological effect is now being found in phytotherapeutic agents, such as $A$. boone $i$ whose $n$-hexane fraction mediated inflammation with less toxicity, compared to ibuprofen in the present study. Steroidal terpenoids were identified in the tested fraction. Recent antiinflammatory studies on phytosterols showed that stigmasterol did not produce a significant anti-inflammatory effect in vitro but performed better in a topical application. ${ }^{50-52}$ The prenylated steroid glycoside (15) has not been tested for anti-inflammation but closely related compounds have been claimed to possess good anti-inflammatory properties. ${ }^{53,54}$ Structural similarity of these steroidal molecules to those of known single agent anti-inflammatory drugs suggests that they may be contributing additively to the notable anti-inflammatory activity of A. boonei's $n$-hexane fraction in the present study. Maslinic acid has been found to suppress LPS-induced release of inflammatory mediators (NO and TNF- $\alpha$ ), normalizing COX-2 and iNOS overexpression. ${ }^{55}$ Similarly, corosolic acid and related pentacyclic triterpenes have been reported as potential anti-inflammatory agents whilst sphingolipids play a significant role in modulation of inflammatory responses. ${ }^{56-58}$ Four of the identified compounds possess nitrogen either as primary amine (6 and 7) or as amide (5 and 9). These nitrogen-bound moieties provide additional drug-receptor binding sites due to reactive lone pairs of electrons. In addition to this, olivetol, identified in this fraction is an important intermediate in the synthesis of cannabinoid, a phytochemical with analgesic and anti-inflammatory property. ${ }^{59}$

There is a structure-function relationship concept that exists between natural products and their biological activity. ${ }^{60}$ So also, hydrophobicity, presence of charges and polarity are some of the factors that determine the efficiency of natural products as effective antioxidants or anti-inflammatory molecules. ${ }^{60}$ Previous studies have indicated that hydrophobicity favours the antioxidant property of a molecule while the presence of charge species would enhance anti-inflammatory potentials of macromolecules. ${ }^{60}$ In this study, similar to what was observed in other studies, ${ }^{61}$ both bulky, hydrophobic and hydrophilic phytochemicals were profiled and this may be responsible for the activity of this plant as a source of natural products with anti-inflammatory potentials.

The chemical fingerprint of $A$. boonei extract in this study revealed strong hydrophobic constituents as would be expected of an $n$-hexane fraction. A reasonable hydrophilic/hydrophobic balance is often required for good anti-inflammatory activity. ${ }^{62,63}$ However, the hydrophobic portion of the extract and interactions of the hydrophobic fragments of multifunctional metabolites enhance cellular permeability, thus increasing the overall bioavailability of the anti-inflammatory agent. ${ }^{62,63}$ Some of these compounds inter-convert with slight changes in $\mathrm{pH}$, temperature and other physical parameters in order to overcome transport/media or cellular barrier. Such is the case with chelerythrine, an anti-inflammatory compound which inter-converts to its alkanolamine derivative to effectively permeate the cell membrane. ${ }^{64-66}$ Having identified compounds ranging from simple, open chain fatty acids to polycyclic and nitrogen-containing terpenoids, the complex but natural "intelligent mixture" of these bioactive compounds being active against multiple targets may be responsible for the observed anti-inflammatory activity of $A$. boonei. 


\section{Conclusion}

In summary, it is concluded that by presenting a more detailed study on the anti-inflammatory potential of $A$. boonei, we hereby validate the indigenous claims of the anti-pyretic and anti-inflammatory potentials of this plant. Furthermore, these pharmacological properties may be traceable to the identified phytochemicals present in this plant. Consequently, the pharmacological properties of these phytochemicals may be attributed to their hydrophobicity, the presence of charge species and functional groups. It shows, further, that although one of the present orthodox non-steroidal anti-inflammatory drugs has been found to increase creatine kinase levels. This may probably be one of the side effects of this drug as corroborated by a previous study. Phytochemicals from this fraction may be optimized and may serve as alternatives to these orthodox antiinflammatory drugs if purified, characterized and standardized.

\section{Abbreviations}

ALT, alanine aminotransferase; AST, aspartate aminotransferase; ATP, adenosine triphosphate; CK, creatine kinase; CRP, C-reactive protein; DNP, dinitrophenol; ELISA, enzyme immunosorbent assay; GGT, gamma glutamyl transferase; IL, interleukin; LPS, lipopolysaccharide; mPT, mitochondrial permeability transition; NTA, no triggering agent; SDS, sodium duodecylsulfate; TA, triggering agent added; TNF, tumor necrosis factor; UHPLC-MS, ultra high performance liquid chromatography tandem mass spectrometry.

\section{Acknowledgments}

Authors acknowledge Mr. F.O. Omotayo of Plant Herbarium, Ekiti State University for the identification of the plant.

\section{Disclosure}

The authors report no conflicts of interest in this work.

\section{References}

1. Abao A, Ondua M, Shai LJ, et al. Inhibition of nitric oxide production and free radical scavenging activities of four South African Medicinal Plants. J Inflamm Res. 2019;12:195-203. doi:10.2147/JIR.S199377

2. Olanlokun JO, Babarinde CO, Olorunsogo OO. Antimalarial properties and peventive effects on mitochondrial dysfunction by extract and fractions of Phyllanthus amarus (Schum. and Thonn) in Plasmodium berghei-infected mice. J Basic Clin Physiol Pharmacol. 2020;32:255. doi:10.1515/jbcpp-2020-0046

3. Olanlokun JO, Bodede O, Prinsloo G, et al. Comparative antimalarial, toxicity and mito-protective effects of Diospyros mespiliformis Hochst. ex A. DC. and Mondia whitei (Hook.f.) Skeels on Plasmodium berghei infection in mice. $J$ Ethnopharmacol. 2021;268:113585. doi:10.1016/j.jep.2020.113585
4. Laloo D, Hemalatha S. Ethno-medicinal plants used for diarrhea by tribals of Meghalaya Northeast India. Pharmacog Rev. 2011;5 (10):147-154. doi:10.4103/0973-7847.91108

5. Johnsy G, Beena S, Kaviyarasan V. Ethnobotanical survey of medicinal plants used for the treatment of diarrhea and dysentery. Int $J$ Med Medi Sci. 2013;3(1):332-338.

6. Maroyi A. Traditional use of medicinal plants in south-central Zimbabwe: review and perspectives. $J$ Ethnobiol Ethnomed. 2013;9:31. doi:10.1186/1746-4269-9-31

7. Singh S, Majumdar DK, Rehan HMS. Evaluation of anti-inflammatory potential of fixed oil of Ocimum sanctum (Holy basil) and its possible mechanism of action. $J$ Ethnopharmacol. 1996;54:19-26. doi:10.1016/0378-8741(96)83992-4

8. Olajide OA, Awe SO, Makinde JM, et al. Studies on the anti-inflammatory, antipyretic and analgesic properties of Alstonia boonei stem bark. J Ethnopharmacol. 2000;71(1-2):179-186. doi:10.1016/S0378-8741(99)00200-7

9. Chen L, Deng $\mathrm{H}$, Cui $\mathrm{H}$, et al. Inflammatory responses and inflammation-associated diseases in organs. Oncotarget. 2018;9 (6):7204-7218. doi:10.18632/oncotarget.23208

10. Takeuchi O, Akira S. Pattern Recognition Receptors and inflammation. Cell. 2010;140:805-820. doi:10.1016/j.cell.2010.01. 022

11. Ramadori G, Moriconi F, Malik I, et al. Physiology and pathophysiology of liver inflammation, damage and repair. $J$ Physiol Pharmacol. 2008;59:107-117.

12. Su GL. Lipopolysaccharides in liver injury: molecular mechanisms of kupffer cell activation. Am J Physiol Gastroent Liver Physiol. 2002;2:54. doi:10.1152/ajpgi.00550.2001

13. Goldstein BI, Kemp DE, Soczynska JK, et al. Inflammation and the phenomenology, pathophysiology, comorbidity, and treatment of bipolar disorder: a systematic review of the literature. J Clin Psych. 2009;70(8):1078-1090. doi:10.4088/JCP.08r04505

14. Miller AH, Maletic V, Raison CL. Inflammation and its discontents: the role of cytokines in the pathophysiology of major depression. Biol Psych. 2009;65(9):732-741. doi:10.1016/j.biopsych.2008.11.029

15. Lindahl B, Toss H, Siegbahn A, et al. Markers of myocardial damage and inflammation in relation to long-term mortality in unstable coronary artery disease. FRISC Study Group. fragmin during instability in coronary artery disease. New Engl J Med. 2000;343(16): 1139-1147. doi:10.1056/NEJM200010193431602

16. Shlipak MG, Fried LF, Crump C, et al. Elevations of inflammatory and pro-coagulant biomarkers in elderly persons with renal insufficiency. Circulation. 2003;107:87-92. doi:10.1161/01.CIR.0000 042700.48769 .59

17. Gupta J, Mitra N, Kanetsky PA, et al. Association between albuminuria, kidney function, and inflammatory biomarker profile in CKD in CRIC. Clin J Am Soc Nephrolog Cjasn. 2012;7:1938-1946. doi:10.2215/CJN.03500412

18. Eckersall PD, Bell R. Acute phase proteins: biomarkers of infection and inflammation in veterinary medicine. Vet J. 2010;185:23-27. doi:10.1016/j.tvj1.2010.04.009

19. Bekkelund SI, Johnsen SH. Creatine kinase is associated with reduced inflammation in a general population: the Tromsø Study. PLoS One. 2018;13(5):e0198133. doi:10.1371/journal.pone.0198133

20. Yang Y, Jiang G, Zhang P, et al. Programmed cell death and its role in inflammation. Mil Med Res. 2015;2:12.

21. Rock KL, Kono H. The inflammatory response to cell death. Annu Rev Pathol. 2008;3:99-126. doi:10.1146/annurev.pathmechdis.3.121 806.151456

22. Galluzzi L, Vitale I, Aaronson SA, et al. Molecular mechanisms of cell death: recommendations of the Nomenclature Committee on Cell Death 2018. Cell Death Differ. 2018;25:486-541.

23. Amarante- Mendes GP, Adjemian S, Branco LM, et al. Pattern recognition receptors and the host cell death molecular machinery. Front. Immunol. 2018;9:2379. doi:10.3389/fimmu.2018.02379 
24. Czabotar PE, Lessene G, Strasser A, et al. Control of apoptosis by the BCL-2 protein family: implications for physiology and therapy. Nat Rev Mol Cell Biol. 2014;15:49-63. doi:10.1038/nrm3722

25. Delbridge AR, Grabow S, Strasser A, et al. Thirty years of BCL-2: translating cell death discoveries into novel cancer therapies. Nat Rev Cancer. 2016;16:99-109. doi:10.1038/nrc.2015.17

26. Akinawo OO, Anyasor GN, Osilesi O. Aqueous fraction of Alstonia boonei de wild leaves suppressed inflammatory response in carrageenan and formaldehyde induced arthritic rats. Biomed Pharmacother. 2017;86:95-101. doi:10.1016/j.biopha.2016.11.145

27. Vega RJS, Xolalpa NC, Castro AJA, et al. Terpenes from natural products with potential anti-inflammatory activity, terpenes and terpenoids. Shagufta Perveen and Areej Al-Taweel. Intechopen. 2018;5:59. doi:10.5772/intechopen.73215

28. Olanlokun JO, Bolaji OM, Agbedahunsi JM, et al. Therapeutic effects of various solvent fraction of Alstonia boonei on P. bergheiinduced malaria in mice. Afri J Med Medi Sci. 2012;41:27-33.

29. Johnson D, Lardy H. Isolation of liver or kidney mitochondria. Methods Enzymol. 1967;10:94-96.

30. Lowry OH, Rosebrough NJ, Farr AL, et al. Protein measurement with the Folin phenol reagent. $J$ Biol Chem. 1951;193:262-275. doi:10.1016/S0021-9258(19)52451-6

31. Lapidus RG, Sokolove PM. Spermine inhibition of the permeability transition of isolated rat liver mitochondria: an investigation of mechanism. Arch Biochem Biophys. 1993;306:246-253. doi:10.1006/ abbi.1993.1507

32. Lardy HA, Wellman H. The catalytic effect of 2, 4-dinitrophenol on adenosine triphosphate hydrolysis by cell particles and soluble enzymes. J Biol Chem. 1953;201:357-370. doi:10.1016/S0021-9258(18)71378-1

33. Bai K, Xu W, Zhang J, et al. Assessment of free radical scavenging activity of dimethylglycine sodium salt and its role in providing protection against lipopolysaccharide-induced oxidative stress in mice. PLOS One. 2016;11(5):e0155393. doi:10.1371/journal.pone.0155393

34. Wang Y, Gong J, Zeng H, et al. Lipopolysaccharide activates the unfolded protein response in human periodontal ligament fibroblassts. J Periodontol. 2016;87(5):e75-81. doi:10.1902/jop.2015.150413

35. Bhattacharyya J, Chowdhury TD, Datta AG. Effect of endotoxin on protein degradation and lipid peroxidation of erythrocytes. J Physiol Pharmacol. 1999;50(2):321-326.

36. Upadhyay A, Amanullah A, Chhangani D, et al. Ibuprofen induces mitochondrial-mediated apoptosis through proteasomal dysfunction Molecular Neurobiol. 2016;53(10):6968-6981. doi:10.1007/s12035015-9603-6

37. Mingatto FE, Santos AC, Uyemura SA, et al. In vitro interaction of nonsteroidal anti-inflammatory drugs on oxidative phosphorylation of rat kidney mitochondria: respiration and synthesis. Arch Biochem Biophys. 1996;334(2):303-308. doi:10.1006/abbi.1996.0459

38. Ren K, Torres R. Role of interleukin -1beta during pain and inflammation. Brain Res Rev. 2009;60(1):57-64. doi:10.1016/j.brainresrev.2008.12.020

39. Barnes TC, Anderson ME, Moots RJ. The many faces of interlukin-6: the role of IL-6 in inflammation, vasculopathy, and fibrosis in systemic sclerosis Systemic systems. Int J Rheumatol. 2011;2011:5486. doi:10.1155/2011/721608

40. Kumar S, Joos G. Boon L Role of tumor necrosis factor- $\alpha$ and its receptors in diesel exhaust particle-induced pulmonary inflammation. Sci Rep. 2007;7:11508. doi:10.1038/s41598-017-11991-7

41. Sproston NR, Ashworth JJ. Role of C-reactive protein at sites of inflammation and infection. Front Immunol. 2018;9:754. doi:10.3389/fimmu.2018.00754

42. Bovil JG. Mechanisms of actions of opiods and non-steroidal anti-inflammatory drugs. Eur J Anaesthesiol Suppl. 1997;2018 (15):9-15. doi:10.1097/00003643-199705001-00003

43. Bellik Y, Boukraâ L, Alzahrani HA, et al. Molecular mechanism underlying Anti-inflammatory and anti-allergic activities of phytochemicals: an update. Molecules. 2013;18:322-353. doi:10.3390/ molecules 18010322
44. Baird MF, Graham SM, Baker JS, et al. Creatine kinae-related muscle damage implications for muscle performance and recovery. J Nutr Metab. 2012;2012:1-13. doi:10.1155/2012/960363

45. Fraga GS, Aidar FJ, Matos DG, et al. Effects of ibuprofen intake in muscle damage, body temperature and muscle power in paralympic powerlifting athletes. Int J Env Res Public Health. 2020;17(14):5157. doi:10.3390/ijerph17145157

46. Kallapura G, Pumford NR, Hernadez-Velasco XH, et al. Mechanisms involved in lipopolysaccharide derived ROS and RNS oxidative stress and septic shock. J Microbiol Res Rev. 2014;2:245.

47. Jimenez MD, Martin MJ. Role of L-Arginine in ibuprofen-induced oxidative stress and neutrophil infiltration in gastric mucosa. Free Rad Res. 2009;38(9):903-911. doi:10.1080/10715760410001705168

48. Kapugi M, Cunningham K. Corticosteroids. Orthopaedic Nursing. 2019;38(5):336-339. doi:10.1097/NOR.0000000000000595

49. Yasir M, Goyal A, Bansal P, et al. Corticosteroid Adverse Effects. StatPearls Publishing LLC; 2020.

50. Thabet AA, Youssef FS, Korinek M, et al. Study of the anti-allergic and anti-inflammatory activity of Brachychiton rupestris and Brachychiton discolor leaves (Malvaceae) using in vitro models. BMC Compl Alt Med. 2018;18(1):1-15.

51. Yuan L, Zhang F, Shen M, et al. Phytosterols suppress phagocytosis and inhibit inflammatory mediators via ERK pathway on LPS-triggered inflammatory responses in RAW264. 7 macrophages and the correlation with their structure. Foods. 2019;8(11):582. doi:10.3390/foods 8110582

52. Garcia MD, Saenz MT, Gomez MA, et al. Topical antiinflammatory activity of phytosterols isolated from Eryngium foetidum on chronic and acute inflammation models. Phyto Res. 1999;13(1):78-80. doi:10.1002/(SICI)1099-1573(199902)13:1<78::AID-PTR384>3.0. $\mathrm{CO} ; 2-\mathrm{F}$

53. Vassallo A, De Tommasi N, Merfort I, et al. Steroids with antiinflammatory activity from Vernonia nigritiana Oliv. \& Hiern. Phytochemistry. 2013;96:288-298. doi:10.1016/j.phytochem.2013. 09.002

54. Choi JN, Choi YH, Lee JM, et al. Anti-inflammatory effects of $\beta$ sitosterol- $\beta$-D-glucoside from Trachelospermum jasminoides (Apocynaceae) in lipopolysaccharide-stimulated RAW 264.7 murine macrophages. Natural Prod Res. 2012;26(24):2340-2343. doi:10.10 80/14786419.2012.654608

55. Huang L, Guan T, Qian Y, et al. Anti-inflammatory effects of maslinic acid, a natural triterpene, in cultured cortical astrocytes via suppression of nuclear factor-kappa B. Eur J Pharmacol. 2011;672 (1-3):169-174. doi:10.1016/j.ejphar.2011.09.175

56. Kim SJ, Cha JY, Kang HS, et al. Corosolic acid ameliorates acute inflammation through inhibition of IRAK-1 phosphorylation in macrophages. BMB Rep. 2016;49(5):276. doi:10.5483/BMBRep.20 16.49.5.241

57. Yang CC, Yang CM. Chinese herbs and repurposing old drugs as therapeutic agents in the regulation of oxidative stress and inflammation in pulmonary diseases. J Inflamm Res. 2021;14:657-687. doi:10.2147/JIR.S293135

58. El Alwani M, Wu BX, Obeid L, et al. Bioactive sphingolipids in the modulation of the inflammatory response. Pharmacol Thera. 2006;112(1):171-183. doi:10.1016/j.pharmthera.2006.04.004

59. Kearsey LJ, Prandi N, Karuppiah V, et al. Structure of the Cannabis sativa olivetol-producing enzyme reveals cyclization plasticity in type III polyketide synthases. FEBS J. 2020;287(8):1511-1524. doi: $10.1111 /$ febs. 15089

60. Rakesh KP, Suhas R, Gowda DC. Anti-inflammatory and antioxidant peptide-conjugates: modulation of activity by charged and hydrophobic residues. Int J Pep Res Thera. 2017. doi:10.1007/s10989-017-9668-3

61. Ramos GF, Amponsah IK, Harley BK, et al. Triterpenoids mediate the antimicrobial, antioxidant, and anti-inflammatory activities of the stem bark of. Reissantia Indica J Applied Pharma Sci. 2021;11 (05):039-048. 
62. Saraiva RA, Araruna MK, Oliveira RC, et al. Topical anti-inflammatory effect of Caryocar coriaceum Wittm. (Caryocaraceae) fruit pulp fixed oil on mice ear edema induced by different irritant agents. J Ethnopharmacol. 2011;136(3):504-510. doi:10.1016/j.jep.2010.07.002

63. Machado JF. Antibiotic activity potentiation and physicochemical characterization of the fixed Orbignya speciosa almond oil against MDR Staphylococcus aureus and other bacteria. Antibiotics. 2019;8 (1):28. doi:10.3390/antibiotics 8010028

64. Bodede O, Shaik S, Singh M, Moodley R. Phytochemical analysis with antioxidant and cytotoxicity studies of the bioactive principles from Zanthoxylum capense (Small knobwood). Anti Cancer Agents Med Chem. 2017;17(4):627-634.
65. Fan L, Fan Y, Liu L, et al. Chelerythrine attenuates the inflammation of lipopolysaccharide-induced acute lung inflammation through NF$\kappa \mathrm{B}$ signaling pathway mediated by Nrf2. Front Pharmacol. 2018;9:1047. doi:10.3389/fphar.2018.01047.

66. Niu X, Mu Q, Li W, et al. Protective effects of chelerythrine against lipopolysaccharide-Induced endotoxic shock in mice. Inflammation. 2014;37:1968-1975. doi:10.1007/s10753-014-9929-7.

\section{Publish your work in this journal}

The Journal of Inflammation Research is an international, peerreviewed open-access journal that welcomes laboratory and clinical findings on the molecular basis, cell biology and pharmacology of inflammation including original research, reviews, symposium reports, hypothesis formation and commentaries on: acute/chronic inflammation; mediators of inflammation; cellular processes; molecular mechanisms; pharmacology and novel anti-inflammatory drugs; clinical conditions involving inflammation. The manuscript management system is completely online and includes a very quick and fair peerreview system. Visit http://www.dovepress.com/testimonials.php to read real quotes from published authors. 